\begin{tabular}{|c|c|}
\hline \multirow{3}{*}{ 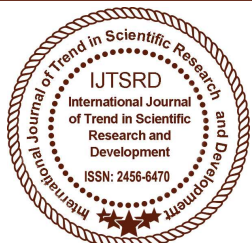 } & International Journal of Trend in Scientific Research and Development (IJTSRD) \\
\hline & International Open Access Journal | www.ijtsrd.com \\
\hline & ISSN No: 2456 - 6470 | Volume - 2 | Issue- 6 | Sep-Oct 2018 \\
\hline
\end{tabular}

\title{
Aluminium Alloy Scraps as Useful Raw Material in Component Manufacturing and the Attendant ILL Effects
}

\author{
P. A. Ukachi, K. E. Ojaomo \\ Department of Mechanical Engineering, The Federal Polytechnic, \\ Ado-Ekiti, Ekiti State, Nigeria
}

\begin{abstract}
Scraps are produced over a period of time due to errors such as mismatch porosity, poor finishing and out of tolerance. More scraps are prone to be produced from one particular metal and alloy more than some others. This paper looks at the importance of scraps especially aluminum alloy scraps and compares it with the chemical composition of finished aluminum products. It also examines the composition of imported component aluminum alloys and chemical composition of aluminum alloys recovered from scraps. The result of chemical composition of both using atomic spectrometer showed very close similarity in properties and ill-effects with aluminum.
\end{abstract}

Keywords: Aluminum alloy, chemical analysis, scraps, test and employees' health.

\section{INTRODUCTION}

Metals are used in a wide variety of applications. They will therefore be in various states when sent for recycling. Sorting and processing of metal scraps is essential because when melted, mixtures of metals may become alloys. Without careful separation, the quality of the final product will reduce. However careful and proper sorting gives improved quality product (Nyior, 2008). Metal recycling is a pyramid industry which includes small family and companies as well as large international business outfits. Operators carry out a lot of functions often, including several of the following activities with smaller operators supplying partially or fully processed metals to large operators and traders. Some of these listed processes may not be required in all cases of scraps processing (Nyior, 2008). Aluminum recycling is a process by which scrap aluminum can be reused in products after its initial production. The process involves simply melting the metal, which is far less

expensive and energy effective than producing new aluminum from the electrolysis of aluminum oxide $\left(\mathrm{Al}_{2} \mathrm{O}_{3}\right)$ which must first be mined from bauxite ore and later refined using Bayer process. Recycling scrap aluminum requires only 5\%of the energy used to make new aluminum. For this reason, approximately $31 \%$ of aluminum produced in United States come from recycled scrap. Most of them are manufactured into aluminum cans. A common practice since the early 1900s and extensively capitalized during World War II indicating that aluminum recycling is not new. It was however a low profile activity until the 1960s, when exploding popularity of aluminum beverage cans finally placed recycling into public consciousness (Wikipedia, 2017). Sources of recycled aluminum include aircrafts, automobiles, bicycles, boats, computers, cook wares, gutters, dump sites and many other products that need a light weight material or - materials with light thermal conductivity. Recycling does not transmute the element aluminum can be recycled repeatedly and still be used to produce any product for which new aluminumcould have been used. The recycling of aluminum generally produces significant cost saving over production of new aluminum even when the cost of collection, separation, and recycling are taken to account. Over the long run, larger national savings are made when the reduction in capital costs associated with landfills, mines and international shipping of raw alumina are considered (Wikipedia, 2017).

\section{Aluminum Scrap}

Aluminum scrap is the most essential input material for the recycle process. It is often categorized as new scrap from production process and old scrap from post-consumer use. New scraps arise from defective aluminum products from manufacturing processes or 
of semi-fabricated final products whereas old scraps refer to those products collected after being used and disposed by consumers. Old scrap is often more contaminated and tedious to reuse than new scrap. End of life vehicles, demolished buildings and constructions, discarded packaging materials, home and office appliances as well as machine equipment are all potential sources of old aluminum scraps (Aluminum, 2018). There is abundant metal scraps in Nigeria especially aluminum scraps which should be serving as useful raw material for our foundry industries especially now that the economy needs diversification. The abundant metal scraps in our country are presently exported. There were illegal attempts in September, 2011 to export four container loads of aluminum scrap valued at over US $\$ 470000$ (Recycle international, 2011). These are raw materials that can be utilized in our manufacturing industries. Aluminum is one of the only materials in the consumer and industrial waste stream that pays for its recycling. This recycling process propels business activity rapidly. (Ukachi, 2016)

\section{Sorting of Aluminum Scraps}

The collection and sorting of aluminum scraps especially old scraps is often a complex scheme involving millions of households, local and regional authorities, small and medium collectors and metal merchants. Waste and environmental policies can also have strong influence on the collection schemes.

Sorted aluminum scrap may need to be separated further and pre-treated before the metal can be recovered in melting furnaces. Separation of aluminum at this stage can be done by various mechanical operations, such as magnetic, gravity, eddy current or colour sensor. Further separation of different aluminum alloys can be achieved through $\mathrm{x}$ ray methods. Wrought alloys and casting alloys are often separated before the mechanical processes where possible (Aluminum, 2018)

\section{Ill - Effects of Aluminum on Humans and Environmental Problems.}

The advantages of aluminum recycling notwithstanding, there are human and environmental problems. Recycling aluminum requires only five percent of the energy required to manufacture new aluminum from bauxite. However, recycling aluminum produces many toxic chemicals that released into the air. Furthermore recycling aluminum produces a waste called "dross" that is highly toxic to be buried in landfills. This dross must be tightly sealed in containers so that it doesn't leak out and enter ground water. In order to recycle aluminum must be melted to separate the pure metal from the impurities. This process produces a waste product known as salt cake. For every ton of aluminum that is melted 200 to 500 kilograms of salt cake are produced. It contains aluminum oxides, metallic aluminum, carbides, nitrides, sulphides and phosphides. Salt cake is highly toxic to living organism (David, 2018).

Occupational exposure to aluminum occurs during the refining of the primary metal and in secondary industries that use aluminum products. Several studies have reported adverse respiratory tract effects in aluminum industry employees. Asthma-like symptoms, known as pot-room asthma have been the most intensive investigated respiratory effect. Wheezing, dyspnea and impaired lungs function are also part of ill effects. Several cross sectional case control and longitudinal studies have demonstrated increased frequency of adverse pulmonary effects in pot-room workersas compared to non-exposed workers (Daniel et al, 2018). It is the most widely distributed metal on the planet and it's used in the production of many every- day products. Cookware is made from aluminum, soda cans are aluminum, and aluminum foil is found in most kitchens. Aluminum is also in antacids, aspirin, vaccines, and even flour. This overwhelming infestation of aluminum means that your risk of exposure is through the roof, which is also made of aluminum. Unlike vitamins, minerals, and trace elements, the body does not need aluminum. And aluminum is no innocent or benign participant. Aluminum accumulates in the kidneys brain, lungs, lever and thyroid where it competes with calcium for absorption and can affect skeletal mineralization. In infants, this can slow growth. And models have linked aluminum exposure to mental impairments. (Edward, 2016)

\section{Materials and Methods}

The essential materials for the study include aluminum alloy scraps, moulding box (cope and drag), pattern of aluminum motorcycle clutch handle and atomic emission spectrometer.

Sand casting method was used to produce aluminum motorcycle clutch handle following standard procedures from moulding to casting and finishing. 
Both the imported and the locally made aluminum alloys of motorcycle clutch handles were subjected to chemical analysis using the atomic emission spectrometer (AES) where the intensity of the of light emitted from plasma flame sparks at a particular wavelength signaling the quality and quantity of elements in each sample.

\section{Results and Discussion}

The result of the chemical analysis of the locally and imported aluminium alloy of motorcycle clutch handle are presented in Tables1 and Table 2. In table 1, Aluminium was found to be $95.41 \%$ but $95.04 \%$ in table 2 with a mere $0.387 \%$ reduction in aluminium content. Other constituents of the alloy are found to be approximately the same as shown in these tables. Further statistical presentations of the results in graphs (Figure 3 \& Figure 4) and pie charts (Figure 5 \& Figure 6)revealed no significant spreading or dipping in composition of the remaining constituent elements. Succinctly, the result showed that there is not much departure in the major chemical content (Al, $\mathrm{Si}$, and $\mathrm{Fe}$ ) of the samples. In Table 1 It is worthy of note that $\mathrm{Si}$ (silica)and $\mathrm{Fe}$ (iron) content are the hardness determinant, environment equally affects this determinants (Nwoye et al, 2010). It is also worthy of note that the cast alloys interact with the sand mould which is rich in silica and iron content, thereby bringing about the material hardness (Bam et al, 2015)

\section{Conclusion}

Locally produced component from scrap aluminium alloy of motorcycle clutch handle has almost the same chemical composition with imported sample of motorcycle clutch handle. This infers that locally sourced scraps are good raw materials for manufacturing aluminium alloy products from recycling. Metal recycling is a multimillion naira industry that provides secondary raw materials for the foundry, metal fabrication and related industries. It is energy efficient, environmentally friendly and provides employment opportunities for many if properly managed.

\section{Recommendation}

From the study it is noted that there is no standard policy for effective streamlining of the scrap recycling industry in Nigeria and government is losing out on the numerous offers in that sector. However, the Nigeria Metallurgical Society (NMS), Nigeria Society of Engineers (NSE), Manufacturing Association of Nigeria (MAN) and related institutions should prepare and push for a policy framework to reposition the industry by maximally harnessing the potentials and turn aluminium scraps to wealth and a non-oil revenue base for the nation. Industries should be encouraged to source their scraps from registered collectors to regulate and control the quality and mechanisms of scrap and to avoid revenue loses and tax evasion. Cooperative groups should be encouraged to set up schemes to provide convenient and central store for collected scraps to avoid littering and environmental issues.

Table 1: The chemical composition of imported aluminium alloy cast handle

\begin{tabular}{|c|c|c|c|c|c|c|c|c|c|c|c|c|c|c|c|}
\hline Elements & Al & Si & Fe & Cu & Mn & Mg & Zn & Cr & Ni & Ti & Sr & Zr & V & Ca & Be \\
\hline$\%$ & 95.41 & 3.2 & 0.8 & 0.3 & 0.2 & 0.04 & 0.1 & 1.5 & 0.06 & 0.08 & - & - & - & - & - \\
\hline
\end{tabular}

Table 2: The chemical composition of locally produced aluminium alloy cast handle

\begin{tabular}{|c|c|c|c|c|c|c|c|c|c|c|c|c|c|c|c|}
\hline Elements & Al & Si & Fe & Cu & Mn & Mg & Zn & Cr & Ni & Ti & Sr & Zr & V & Ca & Be \\
\hline$\%$ & 95.04 & 3.2 & 0.8 & 0.3 & 0.2 & 0.04 & 0.1 & 1.5 & 0.06 & 0.08 & - & - & - & - & - \\
\hline
\end{tabular}




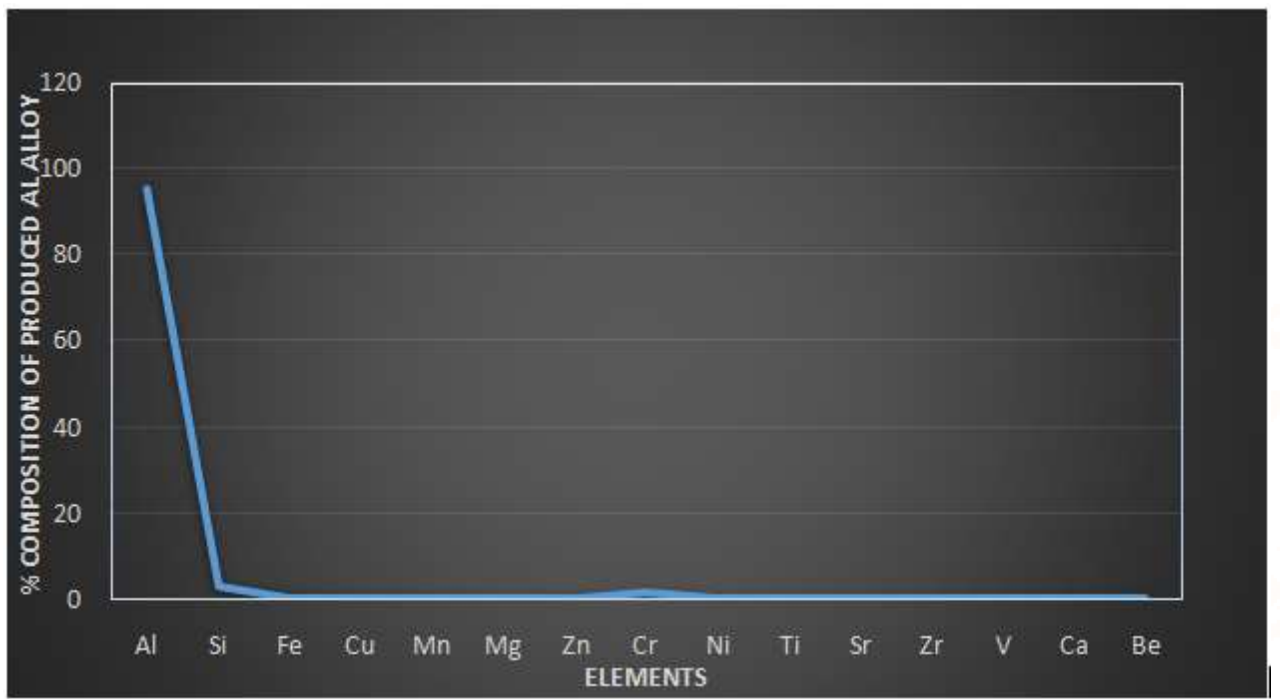

Figure 1: Graphical representation of produced Aluminium alloy composition

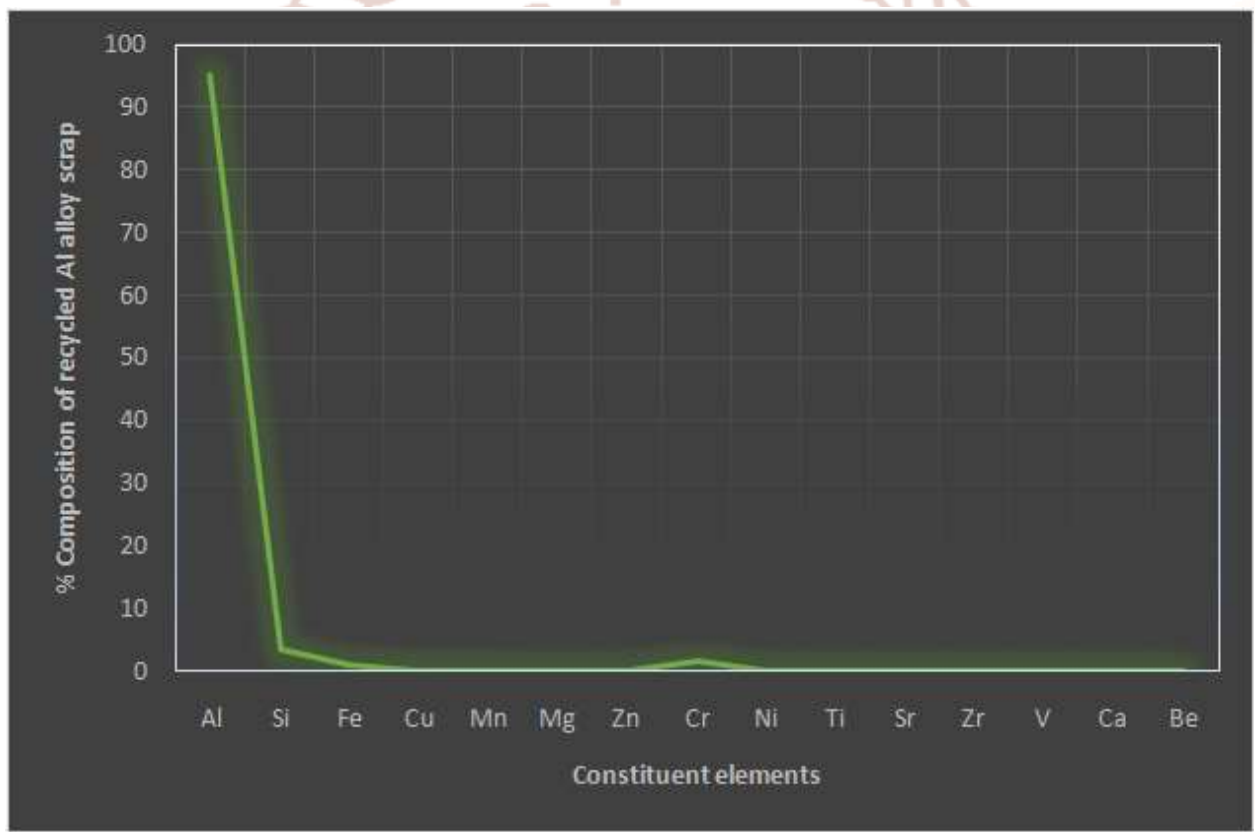

Figure 2: Graphical representation of scrap Aluminium alloy composition

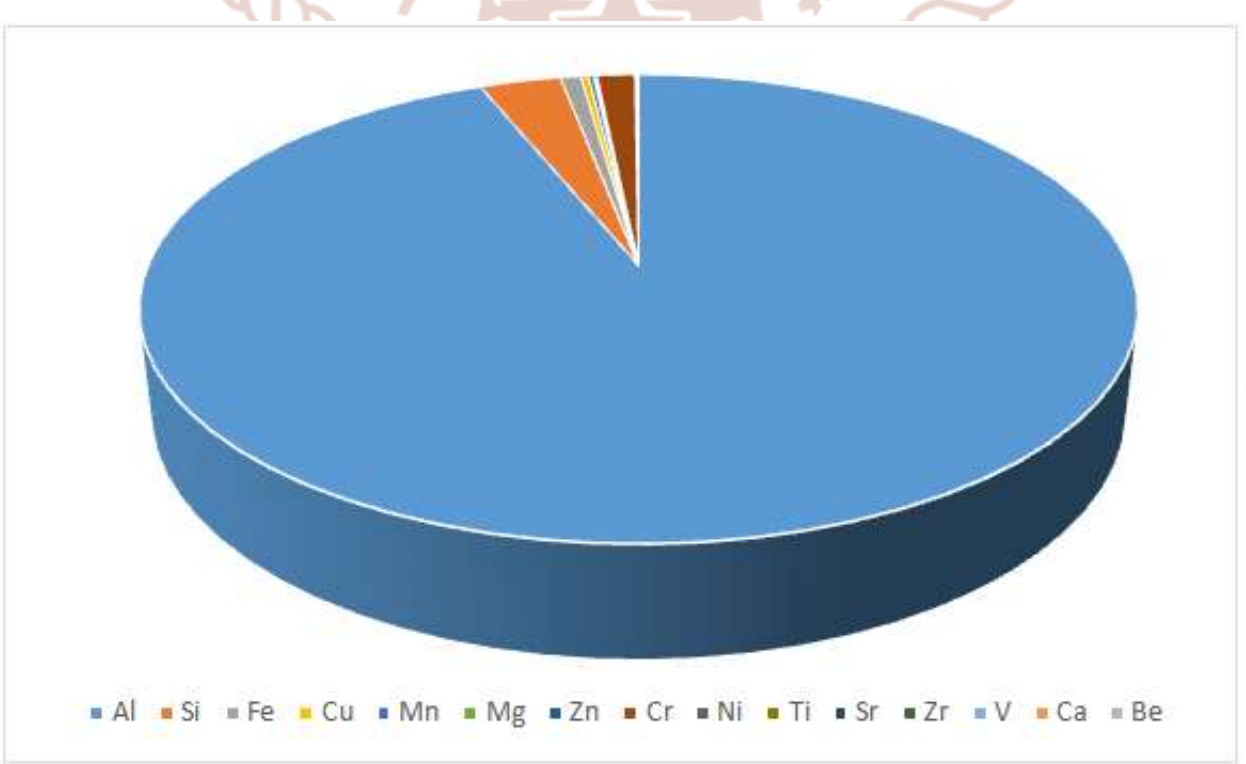

Figure 3: Pie Chart presentation of imported material 


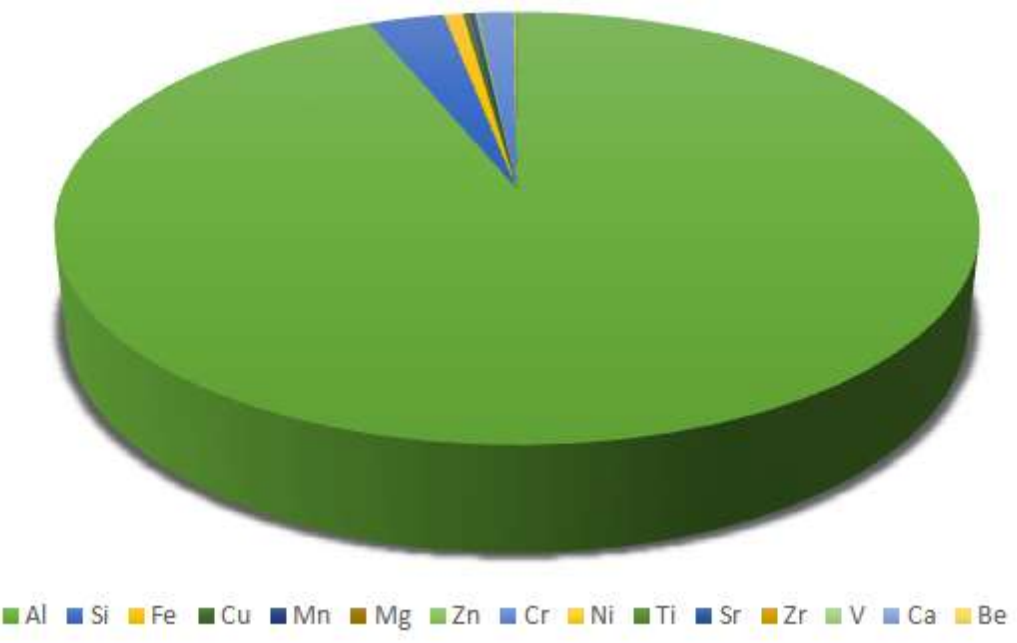

Figure 4: Pie Chart presentation of imported material

\section{References}

1. Aluminum

\section{Recycling} "Aluminum for Future Generations"

(2016) http://recycling.worldaluminium.org/resources/ma terials/Retrieved on 1/25/2018,

2. Bam, S. A. Iortsor, A. and Akaaza, J.N. (2016). Improvement and Comparative Analysis of River Benue Foundry Sand, Using Cassava and Maize as Binders in casting. International Journal of Applied Research. Tamil Nahu India (1) 8 pp $712-$ 714

3. Daniel Krewiski (2018). Human Health Risk Assessment for Aluminium Department of Epidemology and Community Medicine, Faculty of Medicine, University of Ottawa, Ottawa, Ontario, Canada.

7,https://www.ncbi.nlm.nih.gov/pmc/articles/pmc 2782734/. Retrieved on 1/25/2018. 6:34 AM.

4. Nguyen,D.H.(2018) . Environmental Problems Associated with Recycling Aluminium File://c:/users/HP/Downloads/Environmental Problems Associated with recycling. Retrieved on 8/30/2018, 8:37 pm.

5. Global Healing Center (2013), "Why I'm Concerned about the Dangers of Aluminum" http://www.globalhealingcenter.com/naturalheath/concerned-about- Retrieved on 2/18/2016 2:53PM.

6. Nwoye, C. I., Obiegwu, E. O. and Mba, C. N. (2010). Model of Periodic Assessment and Prediction of Otamiri Refractory Designated for Oven Drying Development. Journal of metallurgy and Materials (JMM) Vol. 5 No. 2, pp 48-54
7. Nyior G.B., Dauda G.T. and Muhammed R.A. (2008). Metal Recycling, An Under-tapped Goldmine in the Country. Proceedings of National Metallurgical Society Conference, held on - pp 87

8. Recycle international (2011). Scrap Export Ban Arrests in Nigeria, Retrieved from http://www.recyclinginternational.com/recyclingnews/3865/non-ferrous-metals/nigeria-india/scrapexport-ban-arrests-nigeria.Retrieved 02/07/2016.

9. Ukachi P. A., (2016). Evaluation of the properties of locally produced aluminum alloy motorcycle clutch handle. M. ENG. thesis submitted to the Department of mechanical Engineering, Federal University of Agriculture, Makurdi. Nigeria.

10. Webster P.D. (1980). Fundamentals of foundry Technology. Portcullis Press Ltd, Queensway House. Red hill, Surrey. pp 48Wikipedia,(2017). Aluminum recycling-Wikipedia. https://en.wikipedia.org/wiki/Aluminumrecycling. Retrived on 1/25/2018, 6:02AM. 